\title{
Pain management in bleeding disorders care: perspectives of Canadian Social Workers in Hemophilia Care
}

Jennifer King, Kara Fletcher, Susan M. Tupper, Kelsey Brose, Donna Goodridge

Background: Pain associated with bleeding disorders has been demonstrated to have an impact on patients' and families' quality of life. Both acute and chronic pain are common experiences and require attention by professionals working in haemophilia treatment centres (HTCs). The benefits of psychological pain management strategies such as cognitive behaviour therapy and self-management skills training are well documented; however, it is not well understood how Canadian social workers involved in haemophilia care perceive and provide pain management support to patients. Aims: To explore the current understanding of pain management and practice as well as the education needs of members of Canadian Social Workers in Hemophilia Care (CSWHC). Method:

JENNIFER KING

Health Sciences, College of Medicine, University of

Saskatchewan, Saskatoon; Saskatchewan Health Authority,

Saskatoon, Canada. Email: jls989@mail.usask.ca

KARA FLETCHER

Faculty of Social Work, University of Regina, Saskatoon,

Canada

SUSAN M. TUPPER

Saskatchewan Health Authority, Saskatoon, Canada

KELSEY BROSE

College of Medicine, University of Saskatchewan, Saskatoon; Saskatchewan Cancer Agency, Saskatoon, Canada

DONNA GOODRIDGE

College of Medicine, University of Saskatchewan,

Saskatoon, Canada

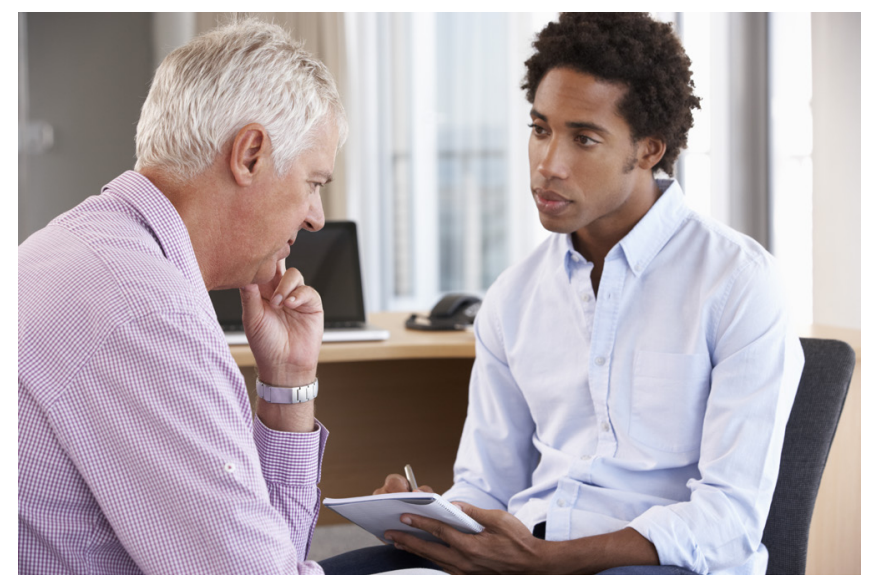

Participants in a study involving members of Canadian Social Workers in Hemophilia Care anticipate that improved knowledge of pain and pain management will have a positive impact on their practice within the multidisciplinary team, and increase their capacity to advocate for people with bleeding disorders.

Twelve semi-structured qualitative interviews were conducted with members of CSWHC. Transcribed interviews were coded with NVivo software and thematically analysed. Results: The four key themes reflecting the experiences of social workers are: 1) Limited comprehension of key issues related to pain; 2) Conditioning to push through pain; 3) Expanding pain knowledge to enhance practice; 4) How we practice social work and choose to step in. Conclusion: The current practice of CSWHC members aligns with literature in three main areas including assessment, instrumental services, and counselling. Social workers support the development of pain education and practical resources for patients

This is an Open Access article distributed under the terms of the Creative Commons Attribution-NonCommercial-NoDerivs License (https://creativecommons.org/licenses/by-nc-nd/3.0/) which permits use and distribution in any medium, provided the original work is properly cited, the use is non-commercial, and no modifications or adaptations are made. Copyright is retained by the authors. 
with haemophilia who experience pain. While formal education, advocacy, and policy development of pain assessment and management are recognised, these areas require further research and development.

Keywords: psychosocial pain management, social workers, bleeding disorders, Canada

dvances in recombinant factor replacement therapy in haemophilia care have increased life expectancy as well as quality of life (QoL); however, bleeds and missed treatments continue to influence acute and chronic pain among people with haemophilia $(\mathrm{PwH})^{[1-3]}$. Due to the nature of chronic pain and the impact it has on QoL, social workers are uniquely situated to take an active role in pain assessment, treatment, and management ${ }^{[4,5]}$. Current literature exposes gaps in the use of validated pain and mental health assessment tools, advocacy, and policy development in social work practice ${ }^{[6]}$.

\section{Pain in bleeding disorders}

Bleeding disorders are inherited and genetic conditions, including haemophilia A, haemophilia B, von Willebrand disease (VWD), and platelet function disorders. Patients with these diagnoses are at increased risk for bleeding into joints, muscles and internal organs, increasing the probability of long-term tissue damage and chronic pain ${ }^{[3,78]}$. Acute pain can result from bleeds, typically associated with swelling, heat and restricted movement, as well as pain from medical procedures including factor infusions ${ }^{[3,89]}$. Chronic pain experienced from permanent joint impairment may arise from damage to the synovial lining or surgical interventions such as joint replacements or fusions ${ }^{[3,8,9]}$. Endogenous pain modulation regulated by the central nervous system influences the pain experience ${ }^{[10,11]}$. The experience of pain in bleeding disorder patients may be amplified by impaired endogenous pain modulation ${ }^{[12]}$. Pain is a subjective experience including physical and psychological factors, yet there is support to define pain in purely psychological terms. Biro (2010), for example, moves beyond the strict biological view of pain and acknowledges that pain may exist in psychological form without physical tissue damage present ${ }^{[13]}$.The biopsychosocial impacts of pain on QoL include relationships ${ }^{[14,15]}$, work/school, housing, health management ${ }^{[15-17]}$, psychological concerns including depression/anxiety, fatigue or stress ${ }^{[14-16,18,19]}$, and finances (transportation/social services) ${ }^{[14,15,18]}$.
The Haemophilia Experiences, Results and Opportunities (HERO) study included 675 adult PwH from ten countries who reported a high prevalence of comorbidities, including arthritis (49\%), and psychological concerns such as stress, fatigue, depression/anxiety (47\%), as well as chronic pain (43\%) either related or unrelated to haemophilia ${ }^{[20]}$. A national study in the US of $764 \mathrm{PWH}$ found that $59 \%$ of participants rely on the haemophilia treatment centres (HTCs) for pain management, while $39 \%$ of participants indicated their pain was not well managed, suggesting that pain is a pervasive issue in this population ${ }^{[21]}$. These studies demonstrate the need for HTC care providers to be skilled in pain assessment and management to ensure appropriate treatment and referrals. Many $\mathrm{PwH}$ can find it challenging to distinguish between chronic pain and what could plausibly be an acute bleed ${ }^{[21]}$, suggesting a need for the professionals who work with them to assist $\mathrm{PwH}$ in developing knowledge of pain experiences and the language to describe them. Pain in PwH is widely recognised, and HTC social workers have the potential to provide support and skills to address these concerns.

\section{Social work practice in haemophilia care and pain management}

The predominant effort of the Canadian Hemophilia Society (CHS) has been to improve patient-centred care and QoL while supporting the search for a cure ${ }^{[22]}$. The standard of practice for Canadian Social Workers in Hemophilia Care (CSWHC) includes psychosocial assessment, counselling/psychotherapy, advocacy, education and resources (patient, family and community), support and discharge planning ${ }^{[23]}$.

Current literature on the role of social work in the management of chronic pain demonstrates its impact on QoL and the needs for appropriate intervention ${ }^{[24-26]}$. Social workers routinely conduct psychosocial assessments in these areas and are well situated to assess the impact of pain on QoL and provide intervention services.

This paper explores the understanding and application of the role of members of CSHWC in pain management and the direction of future disciplinespecific pain education.

\section{AIMS}

As there is a need for $\mathrm{PwH}$ to receive adequate pain management from the HTC, it was important to explore the current understanding and practice of social work in pain management. The aim of this study was to determine the scope of pain knowledge and current 
practice in pain management among social workers in CSWHC, guided by two research questions:

- What do social workers in CSWHC currently understand about pain and bleeding disorder care and their practice?

- What specific pain knowledge and training is prioritised by social workers in CSWHC?

\section{METHOD}

The study was designed by a member of CSWHC and supported by the interest of its membership. A purposive sample was drawn from CSWHC membership (15-20 active members), who have specialised expertise in bleeding disorder care. Participants were recruited during CSWHC's 2018 annual general meeting, where an invitation poster and consent form were distributed, and via email. Twelve social workers agreed to participate in the study.

Semi-structured interviews were conducted with study participants to allow them to reflect on and share their professional experience. An interview guide (Appendix) was developed through discussion of the research questions among the research team. The questions aimed to obtain an understanding of social workers' current knowledge and experience around pain management. No pilot interviews were undertaken due to time restraints.

Participants were invited to interview via email. Interviews were conducted between September 2018 and February 2019 by a single interviewer (JK) in a private home office via Zoom.us and recorded, with participants' consent, to a password-protected computer. Field notes were kept during and after each interview. The interviews were subsequently transcribed by a research service at the University of Saskatchewan and reviewed for accuracy.

Interview transcripts were emailed individually to each participant for review and asked to confirm consent for the transcript and to provide any further comments to clarify their interview.

\section{Ethics}

The University of Saskatchewan Behavioral Ethics Board granted an exemption for this study.

As members of CSWHC, participants were involved in initial discussions about the research; however, they were not involved in finalising the research or in developing the interview questions. Participants signed and submitted informed consent to the interview (JK) in person at the 2018 CSWHC annual general meeting, or via fax or email. The consent form included the granting of permission to use quotes in publications. Participants received gift cards an honorarium for their time. This was approved through ethics and described in the consent form.

\section{Data analysis}

Funding to complete a scoping review and thematic analysis of the interviews was secured through the CHS and Novo Nordisk Psychosocial Research Grant in 2018.

NVivo software was used to manage and analyse data, including the organisation and arrangement of codes and themes. Field notes recorded during the interviews were read prior to the analysis. Clarifying comments received from participants following the receipt of interview transcripts were not included in the analysis.

Data analysis was conducted using a thematic approach. Four considerations were applied to the analysis ${ }^{[27-29]}: 1$ ) inclusion of the entire data set in the analysis using a rich thematic description ${ }^{[27,29]}$. 2) inductive approach using a rich thematic description [27]: 3) utilising a shared meaning in the identification of themes ${ }^{[27-29]}$ : 4) using an essentialist approach to allow inference of theories or ideas from within the data set ${ }^{[27]}$.

Table 1. Participant demographic information ( $\mathrm{N}=12)$

\begin{tabular}{l|l} 
CHARACTERISTIC & N \\
Gender & 2 \\
Male & 5 \\
Female & 5 \\
No response & \\
\hline Age Range & 1 \\
$20-29$ & 2 \\
$30-39$ & 1 \\
$40-49$ & 5 \\
$50-59$ & 1 \\
$60-69$ & 2 \\
No response & \\
\hline Educational preparation & 2 \\
BSW & 7 \\
MSW & 4 \\
Additional degrees & 2 \\
No response & \\
\hline Years of practice & 2 \\
$0-10$ & 2 \\
$11-20$ & 3 \\
$21-30$ & 3 \\
$31-40$ & 2 \\
No response & \\
\hline Additional pain education & \\
Yes & 2 \\
No & \\
No response & \\
\hline & \\
\hline
\end{tabular}




\section{RESULTS}

Interviews were conducted with 12 registered social workers, representing five provinces across Canada, with a range of age, education, and experience. The demographic characteristics of the sample appear in Table 1. All participants worked in an HTC at the time of the interviews. Two indicated that they worked in a combined adult and paediatric clinic, while five indicated working in paediatric clinics. The other five participants did not explicitly indicate the nature of the clinic in which they worked; however, based on the interviews, the research team inferred that they worked within the adult population.

Four themes were identified in the analysis (see Figure 1): 1) Limited comprehension of key issues related to pain; 2) Conditioned to push through pain; 3) Expanding pain knowledge to enhance practice; 4) How we practice social work and choose to step in.

\section{Limited comprehension of key issues related to pain} This first theme emerged through the language social workers used to describe and differentiate between what they described as physical pain or emotional pain. The way in which participants articulated acute and chronic pain within bleeding disorders focused on tissue damage associated with physical injury. They established the connection of emotional pain with physical pain yet did not discuss the bidirectional effects or the influence of emotions on the pain experience. The development of this theme explored how social workers comprehend pain management, contributing to the analysis of both research questions. Examination of language used by participants provided the opportunity to explore gaps in their pain knowledge. When considered with the third theme, this helps to provide an understanding of the education required.

While four participants identified bleeds as a cause of pain, only one identified needles and procedures as a source of pain. One participant showed some uncertainty about how pain occurs from a bleed:

\section{"A joint bleed as an example of that which can result from trauma. Essentially blood, I believe, being released into the joints causing much pain." (P001)}

Also noted was the application of a pain intensity scale to differentiate between acute or chronic pain:

"Chronic pain, in my opinion, is probably something that's above a six or seven on a one to ten rating of scale, but it can be higher... I see acute pain being the spike, so it goes from let's say a two to an eight back down to a two, right?" (P002)

Few participants identified joint damage due to recurrent bleeds, and there was no discussion of the specifics of how this occurs. The language participants used to describe chronic pain indicated a limited comprehension of pain language, for example:

"Just the lack of relief from the pain. It's always there." (P011)

Five participants went beyond physical pain and discussed the emotional response and impact of pain. Emotional pain was identified as a concern for participants:

\section{"Sometimes physical pain can also contribute to an emotional, psychosocial pain that, you know, once the physical pain has healed, there could be that psychological pain." (P010) \\ "The pain isn't always physical; sometimes there's some emotional pain associated with this as well." (P011)}

Strong emotional words were used to describe chronic pain in bleeding disorder patients:

"[...] persistent, always there. Constant reminder that I have an issue. Depressing, disappointing." (P004)

Another participant articulated their lack of pain understanding:

"I don't know that l've ever heard us define it, so, therefore, I'm having trouble actually knowing if that is the correct definition of it." (P008)

The social workers in our study also reported that their time dedicated to bleeding disorders care is limited, and that they cover other areas of the hospital away from their specific disease expertise.

\section{Conditioned to push through pain}

One of the interview questions asked about what messages participants hear about pain from society, patients, health care providers or their own families. 
Many participants spoke to their own experience growing up. One participant used the example of sports activity:

"I was an athlete, so pain was always something that you - you suck it up." (P002)

Specifically, the need to push through pain was discussed by two participants:

"I think the other messaging within our family was, you sort of need to push through it." (P005).

The perceived thoughts and attitudes of broader social and health care professionals were addressed:

"I think for the hospital's perspective we really don't like to see people in pain, so we treat their pain. I think that's a North American, or Western approach to pain, is that we want it to go away." (P007)

"As a North American society, we're kind of dismissive of the impact of chronic pain and how that impacts a person's sense of self and just quality of life really." (P012)

Participants used self-reflection during the interviews and identified the need to challenge this thinking when it comes to the messages they give to patients experiencing pain. They considered how these messages could impact how they relate to patients in pain through empathy and through providing patients with new messages on pain identification and management. This change and its impact on patients was explored by P005, who described the approach to pain in their upbringing:

"You don't surrender to pain, you push through, you keep going, you be tougher than it is. So, you know, I've had to re-learn what I would say to patients." (P005)

\section{Expanding pain knowledge to enhance practice} Participants noted how learning opportunities in pain management could benefit their patients, impact their practice, and strengthen their role in the multidisciplinary team (MDT). Learning about the specifics of bleeding disorders and pain management, and the development of resources for patient services, was of utmost interest. However, participants wanted to know whether this pain knowledge would transfer into other areas of hospital work, indicating the shared role they have among other specialities and a desire to make the most of educational opportunities.

A need for more specific information on diagnosis was identified:

"to understand individually how the different severities in haemophilia $A$, haemophilia $B$, how that impacts each patient... really understanding that myself so that that education can be supported or provided in the patient." (P001)

Knowledge of specific pain types within bleeding disorders was deemed necessary to assist in discerning potential outcomes and communicating these to patients. One participant suggested:

"...some sort of in-service [training] or maybe some recommended readings, or that sort of thing, on what is pain in terms of haemophilia in patients... what are the solutions or things that will make it easier." (P009)

The impact pain education might have on the role of social work within the multidisciplinary team was similarly reported:

\section{"If I had more knowledge around the whole pain assessment piece, I would be able to maybe assess or have input earlier on with the diagnosis." (P006)}

"Right now, I usually leave it [pain] up to those areas, those disciplines, but I think if I had more knowledge, I would be more vocal and more active in reinforcing, I guess, maybe the treatment plans." (P006)

Consideration was given to the type of pain education that would be helpful:

"I think probably something that would give me an overall guide about pain, what is it, how medically it can be treated, what can we do to assist or lessen pain, how we can teach our patients to deal better with pain and our staff actually as well." (P004)

Participants indicated they would like to have strategies and resources for their interactions with patients, which would benefit both social workers and patients: 
"More written resource information to perhaps give them, to expand their knowledge, and some additional tools that they can use themselves to help support themselves through that aspect of their haemophilia." (P005)

Participants were asked to identify the area of pain knowledge that would be most helpful based on the International Association for the Study of Pain (IASP) Social Work Curriculum Outline ${ }^{[4]}$. Of the four learning categories suggested, the multidimensional nature of pain was the most requested (8 participants), followed by pain assessment and measurement ( 5 participants), and management of pain (2 participants). The fourth category, clinical conditions, was not identified as a useful learning area by any participants.

Participants believed they would benefit from specific pain education, but appeared to have difficulty in saying that it was necessary or crucial, instead stating it would "enhance" (P004), be "important" (P001; P003; P005; P007), they "would be interested" (P006), or it would be "beneficial" (P008; P012). One participant stated specifically that social work requires involvement with patient care "so that we can address that more psychological [aspects], underlying pain" (P010); no participants stated that this would not or should not be part of their role.

Participants reflected on the positive impact that pain education would have not only on patient care but also on their own role within the MDT. They anticipated how pain education could strengthen their role in patient care, specifically knowing how to talk about pain with patients and how to use the language of pain to advocate for them. This would also impact on their role in pain management in the comprehensive care team.

\section{How we practice social work and choose to step in} Consistencies in social work roles across Canada were evident in the interviews. Participants did not hesitate when describing the role of social work and most agreed on the core aspects. Three capacities were identified in their scope of practice: assessor, facilitator of instrumental work, and counsellor/therapist. As discussed in the introduction, these roles align closely with those identified in a scoping review ${ }^{[6]}$.

Participants were unfamiliar with available assessments for pain, but maintain the routine use of psychosocial assessment. They explained their roles in terms of "completing a psychosocial assessment", "ensuring they have connections to appropriate community resources", and "counselling around any issues that might arise" (P005). The instrumental role also includes "medication coverage, sometimes accommodation, transportation needs", "systems navigation, advocacy", and "illness adjustment strategies for coping, difficulties that someone might have in the workplace, something that they might have at home, in their relationship" (007).

Participants identified that social workers could be more active in pain management. The instrumental role was described as being "a good advocate for the family to make sure that they're understanding and making sure our team's doing appropriate education" (P008), but this advocacy requires looking into the areas that pain impacts.

\section{"It's not just pain, it's the effect on their [patients'] mental health that it has, it's the effect on their activities of daily living, it's the effect on their ability to hold and maintain employment or education... social work should play a larger role in that." (P009)}

Multidisciplinary or interdisciplinary teamwork were referred to. Understanding the role of each member in order to provide best practice in the team was the central interest:

\section{"I do have a different perspective and appreciate the perspective of the many other team members, so I think we end up complimenting each other in terms of our practice with our clients." (P011)}

Social workers anticipated future education to have a positive impact on their practice within the MDT, including their capacity for patient advocacy.

\section{DISCUSSION}

Social workers in CSWHC were interested in and open to discussing the current position of pain knowledge and considerations in prioritising education. Reflecting on the research questions, we found in our thematic analysis that the participants interviewed have a limited comprehension of key issues related to pain. Participants' partial discussion of bleeds and causes of muscle or joint pain, and their lack of identifying needles or procedures as pain-producing also evidenced their limited comprehension of pain in bleeding disorder care and came as a surprise to the researchers. The language used to describe acute or chronic pain and the use of 
pain rating scales indicated a requirement for further education, including the relationship of physical and emotional properties of pain.

Pain rating scales determine the subjective nature of pain in the moment and provide assessment for pain intensity and effect ${ }^{[30]}$ but cannot determine whether pain is chronic or acute. Pain scales and assessment of psychosocial functioning are suggested for the assessment of pain by professionals ${ }^{[24,25,31]}$ Understanding the assessment of pain in acute and chronic conditions is required for comprehensive care. The disclosure by P008 showing lack of knowledge around pain definitions exposes a need to develop education and pain literacy for social workers working in bleeding disorders care. The literature supports this call for further education in pain knowledge for social workers ${ }^{[32,33]}$. Also required is general knowledge of health reform and community health ${ }^{[34]}$. Social workers must go beyond patient advocacy and make a call to universities and workplace management in order to fill this gap and provide superior care.

The second finding of this research is that the practice of social work in CSWHC aligns with the literature noted in the introduction of pain-specific interventions; these include assessment, instrumental services, and counselling. Participants were unaware of pain assessment tools and enquired about what was available, although they conducted psychosocial assessments and were clear on the necessity to apply them in practice. They spoke to the instrumental services and counselling services they can provide and expressed a desire to engage in best practices for their clients, also indicating a desire to learn. Participants also used self-reflection and past educational experiences to create changes in their pain beliefs to offer professional care. Allowing time for self-reflection on the messages we receive about pain and how these impact the care of patients is an important exercise in professionalism.

Our third theme, expanding pain knowledge to enhance practice, supported the need for further education for social workers on validated pain assessment tools and outcome measures. Participants recognised this and were clear on the potential benefits to their practice and their patients of education specific to pain, although social workers may find it challenging to advocate for their own educational needs, in part because of limited time, resources, and education funds. The IASP Curriculum Guideline for Social Workers ${ }^{[4]}$ outlines several tools to support pain intervention. Alongside this, further educational outcomes could be identified through the findings of
Theme 1, in which gaps in knowledge were determined based on descriptions of pain and management of pain management of pain in general and with bleeding disorders care in particular.

While the results of this study were encouraging, in that participants were knowledgeable about their role, interested in further education, and open to selfreflection, an unexpected finding arose: there was a lack of use of specific pain terms for bleeding disorders around joint or muscle bleeds, needle or procedural pain, and surgery for joint fusion or replacements. Two possible reasons for this are that social workers are not involved in these types of concerns by team referrals, or they have insufficient time to respond to these types of issues due to shared time with other specialties. Buckner et al. ${ }^{[35]}$ recognised that patients identified a need for further pain education among care providers; in particular, education of non-pharmacologic treatments among bleeding disorder providers is required in order to meet the needs of persons with bleeding disorders.

\section{Future research}

Participants acknowledged that an insufficient amount of education limited their understanding of pain in their social work practice; however, they are keen for this gap to be filled. This deficit of knowledge fundamentally begins within educational curricula, requiring further research on how targeted pain education would directly impact social work practice with individuals, families and societies, and the forward development of advocacy and policy change. Research and development of training programmes in universities are necessary as the impact of pain is far-reaching in QoL and seen in every area of health and social welfare.

The development of a specific pain course for CSWHC members, with research examining the full impact of such training on their professional work within HTCs for patient and comprehensive care teams, would be a next step for this particular project. This would support further advocacy and development of policy for social workers in pain management.

\section{Strengths and limitations}

CSWHC is a small group of social workers dedicated to serving patients in many areas including bleeding disorders. Using a qualitative study design enabled the contribution of valuable information to further the practice of social work. The small group allowed the researchers to interview all those interested in participating in the study, providing an opportunity to reflect on their beliefs and assess the research questions. 
The sample for this study was drawn from a specialised group of social workers who work a modest full-time equivalency in their bleeding disorder role, potentially impacting on how they responded to questions specific to bleeding disorders. Due to the specific nature of the study and the limited number of participants, findings cannot be generalised to other areas of social work practice.

\section{CONCLUSION}

The focus of this qualitative study using thematic analysis was to understand the current understanding of pain in bleeding disorder care among social workers in CSWHC, and to explore the type of pain education social workers would prioritise. Participants used the interviews as a time for self-reflection, allowing thoughtfulness towards how new pain education might change their beliefs and impact on their day-today practice. Social workers are looking for practical resources, including assessment tools, to support their instrumental work and elevate their contribution in pain management. To this end, we encourage further research and development of tools and knowledge to assist social workers working within comprehensive care teams.

\section{ACKNOWLEDGEMENTS}

We would like to thank and acknowledge the support of Canadian Social Workers in Hemophilia Care (CSWHC), the Saskatchewan Bleeding Disorder Program (LiveWell with Chronic Diseases, Saskatchewan Health Authority), and patients for their inspiration.

This work was supported by the Canadian Hemophilia Society CHS-Novo Nordisk Psychosocial Research Grant.

Jennifer King is a member of the Canadian Social Workers in Hemophilia Care (CSWHC); Dr Kelsey Brose is a member of The Association of Hemophilia Clinic Directors of Canada (AHCDC).

Informed consent has been obtained from the participants in the study reported in this paper.

\section{ORCID}

Jennifer King (ID) https://orcid.org/0000-0001-8045-8019 Kara Fletcher (iD) https://orcid.org/0000-0002-6409-7476 Susan M. Tupper (ID) https://orcid.org/0000-0003-3736-357X Kelsey Brose (iD https://orcid.org/0000-0001-6995-5444 Donna Goodridge (iD https://orcid.org/0000-0002-8680-8646

\section{REFERENCES}

1. Lambing A, Nichols CD, Munn JE, Anderson TL, Tortella BJ, Witkop ML. Patient, caregiver, and provider perceptions of pain and pain management in adolescents and young adults with bleeding disorders. Haemophilia 2017; 23: 852-60. doi: 10.1111/hae.13293.

2. McLaughlin JM, Witkop ML, Lambing A, Anderson TL, Munn J, Tortella B. Better adherence to prescribed treatment regimen is related to less chronic pain among adolescents and young adults with moderate or severe haemophilia. Haemophilia 2014; 20: 506-12. doi: 10.1111/hae.12360.

3. Young G, Tachdjian R, Baumann K, Panopoulos G. Comprehensive management of chronic pain in haemophilia. Haemophilia 2014; 20(2): 113-20. doi: 10.1111/hae.12349.

4. International Association for the Study of Pain. IASP curriculum outline for pain in social work. 2018. Available from https://www.iasp-pain.org/Education/CurriculumDetail. aspx? ItemNumber=4956 (accessed 23 April 2020).

5. National Association of Social Work. NASW statement on integrative pain management for the Integrative Pain Care Policy Congress. September 8, 2017. Available from https://www.socialworkers.org/LinkClick. aspx?fileticket=uj5ApiqwXas\%3d\&portalid=0 (accessed 23 April 2020).

6. King J, Fletcher K, Tupper S, Brose K, Goodridge D. The current practice of social work in pain management: a scoping review on chronic disease. 2020. Manuscript submitted for publication.

7. Canadian Hemophilia Society. Bleeding disorders. Available from https://www.hemophilia.ca/bleeding-disorders/ (accessed 23 April 2020).

8. Hemophilia Federation of America. Joint damage. Available from https://www.hemophiliafed.org/understandingbleeding-disorders/complications/joint-damage/ (accessed 23 April 2020)

9. Canadian Hemophilia Society. Joint damage. Available from https://www.hemophilia.ca/joint-damage/ (accessed 23 April 2020).

10. Ossipov MH, Dussor GO, Porreca F. Central modulation of pain. J Clin Invest 2010; 120(11): 3779-87. doi: 10.1172/ JCl43766.

11. Staud R. The important role of CNS facilitation and inhibition for chronic pain. Int J Clin Rheumtol 2013; 8(6): 639-46. doi: 10.2217/ijr.13.57.

12. Kruger S, Hilberg T. Understanding the pain profile in patients with haemophilia: impaired descending pain inhibition as measured by conditioned pain modulation. Haemophilia 2020; 26(2): 236-42. doi: 10.1111/hae.13939.

13. Biro D. Is there such a thing as psychological pain and why it matters. Cult Med Psychiatry 2010; 34: 658-67. doi: 10.1007/ s11013-010-9190-y.

14. MacDonald JE. A deconstructive turn in chronic pain treatment: a redefined role for social work. Health Soc Work 2000; 25(1): 51-8. doi: 10.1093/hsw/25.1.51.

15. Stensland M, Sanders S. "It has changed my whole life": The systemic implications of chronic low back pain among older adults. J Gerontol Soc Work 2018; 61(2): 129-50. doi: 10.1080/01634372.2018.1427169.

16. Aho H, Kauppila T, Haanpaa M. Patients referred from a multidisciplinary pain clinic to the social worker, their general health, pain condition, treatment and outcome. Scand J Pain 2010; 1(4): 220-6. doi: 10.1016/j.sjpain.2010.09.009.

17. McBee $L$, Westreich $L$, Likourezos A. A psychoeducational relaxation group for pain and stress management in the 
nursing home. J Soc Work Long Term Care 2004; 3(1): 15-28. doi: 10.1300/j181v03n01_03.

18. Park J, Hirz CE, Manotas K, Hooyman N. Nonpharmacological pain management by ethnically diverse older adults with chronic pain: barriers and facilitators. J Gerontol Soc Work 2013; 56(6): 487-508. doi: 10.1080/01634372.2013.808725.

19. Works T, Jones S, Grady J, Andemariam B. Traumatic exposure history as a risk factor for chronic pain in adult patients with sickle cell disease. Health Soc Work 2014; 41(1): 42-50. doi: 10.1093/hsw/hlv085.

20. Forsyth AL, Gregory M, Nugent D, et al. Haemophilia Experiences, Results and Opportunities (HERO) study: survey methodology and population demographics. Haemophilia 2013; 20(1): 44-51. doi: 10.1111/hae.12239.

21. Witkop M, Lambing A, Divine G, Kachalsky E, Rushlow D, Dinnen J. A national study of pain in the bleeding disorders community: a description of haemophilia pain. Haemophilia 2012; 18(3): 115-9. doi: 10.1111/j.1365-2516.2011.02709.x.

22. Canadian Hemophilia Society. CHS History. Available from https://www.hemophilia.ca/chs-history/ (accessed 23 April 2020).

23. Canadian Hemophilia Society. Standards of practice. Available from https://www.hemophilia.ca/standards-of-practice/ (accessed 23 April 2020).

24. Turk DC, Audette J, Levy RM, MacKey SC, Stanos S. Assessment and treatment of psychosocial comorbidities in patients with neuropathic pain. Mayo Clin Proc 2010; 85(3): S42-50. doi: $10.4065 / \mathrm{mcp} .2009 .0648$.

25. Hruschak V, Cochran G. Psychosocial and environmental factors in the prognosis of individuals with chronic pain and comorbid mental health. Soc Work Health Care 2017; 56(7): 573-87. doi: 10.1080/00981389.2017.1326074.

26 Duenas M, Ojeda B, Salazar A, Mico JA, Failde I. A review of chronic pain impact on patients, their social environment and the health care system. J Pain Res 2016; 9: 457-467. doi: 10.2147/JPR.S105892
27. Braun V, Clarke V. Using thematic analysis in psychology. Qual Res Psychol 2006; 3: 77-101. doi: 10.1191/1478088706pq063oa.

28. Braun V, Clarke V, Hayfield N, Terry G. Thematic analysis. In: Liamputtong $P$ (ed.) Handbook of Research Methods in Health Social Sciences. Singapore: Springer, 2019: 843-860. doi: 10.1007/978-981-10-5251-4_103.

29. Nowell LS, Norris JM, White DE, Moules NJ. Thematic analysis: striving to meet the trustworthiness criteria. Int J Qual Methods 2017; 16: 1-13. doi: 10.1177/1609406917733847.

30. Haefeli M, Elfering A. Pain assessment. Eur Spine J 2006; 15 : S17-S24. doi: 10.1007/s00586-005-1044-x.

31. Fillingim RB, Loeser JD, Baron R, Edwards RR. Assessment of chronic pain: domains, methods and mechanisms. J Pain 2016; 17(9): T10-T20. doi: 10.1016/j.pain.2015.08.010.

32. MacDonald JE. Anti-oppressive practices with chronic pain suffers. Soc Work Health Care 2008; 47(2): 135-56. doi: 10.1080/00981380801970285.

33. Sieppert J. Attitudes toward and knowledge of chronic pain: a survey of medical social workers. Health Soc Work 1996; 21(2): 122-30. doi: 10.1093/hsw/21.2.122.

34. Browne T, Keefe RH, Ruth BJ, Cox H, Maramaldi P, Rishel C, et al. Advancing social work education for health impact. Am J Public Health 2017; 107(Suppl 3): S229-S235. doi: 10.2105/ AJPH.2017.304054

35. Buckner TW, Durben N, Humphrey C, et al. Pain in the bleeding disorders community: patient and caregiver perspectives. Blood 2016; 128(22): 2591. doi: 10.1182/blood. V128.22.2591.2591.

HOW TO CITE THIS ARTICLE:

King J, Fletcher K, Tupper SM, Brose K, Goodridge D. Pain management in bleeding disorders care: perspectives of Canadian social workers in haemophilia care. J Haem Pract 2020; 7(1): 110-120. https://doi.org/10.17225/ jhp00163.

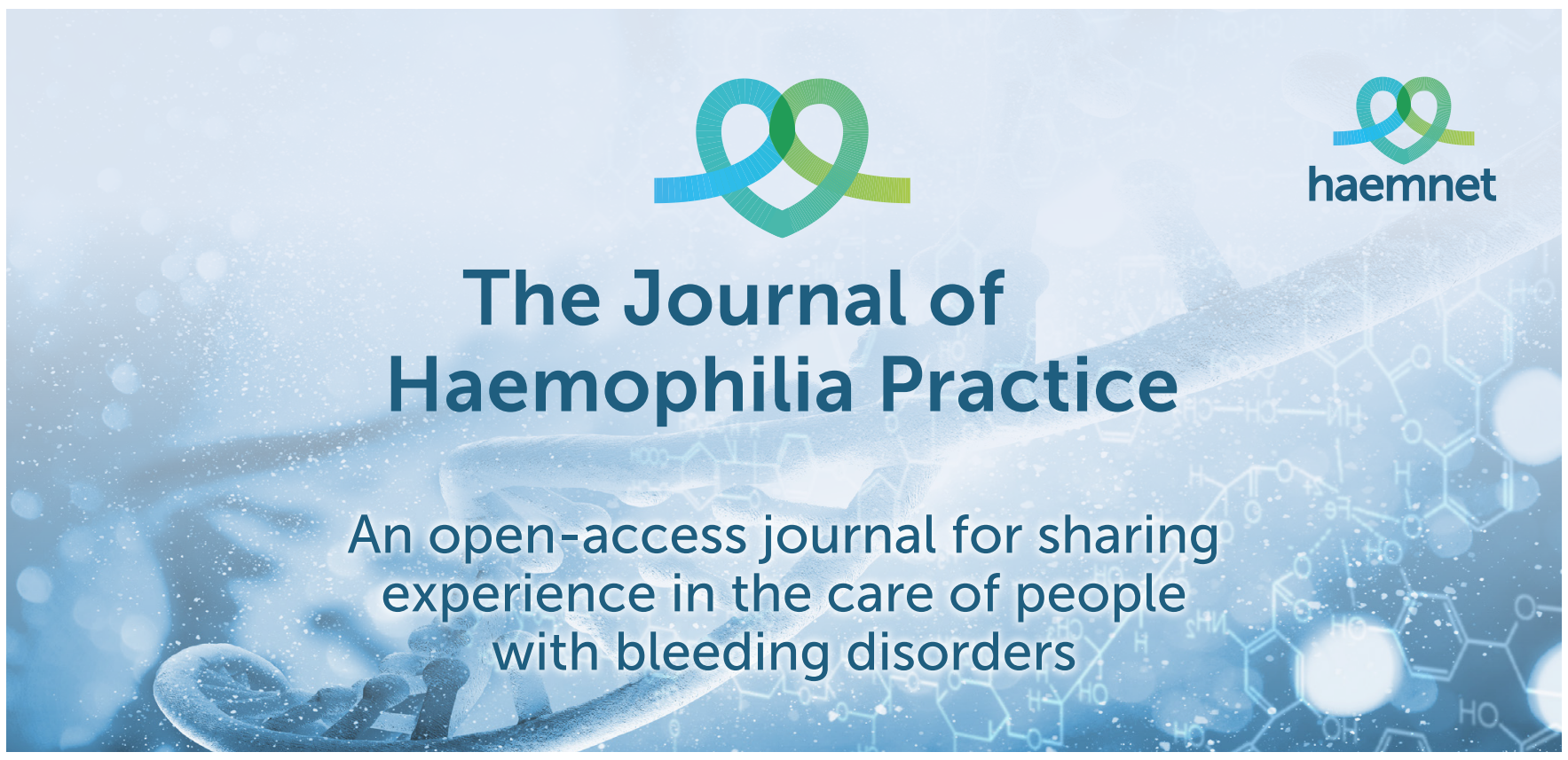


Figure 1

Initial codes first and second coder

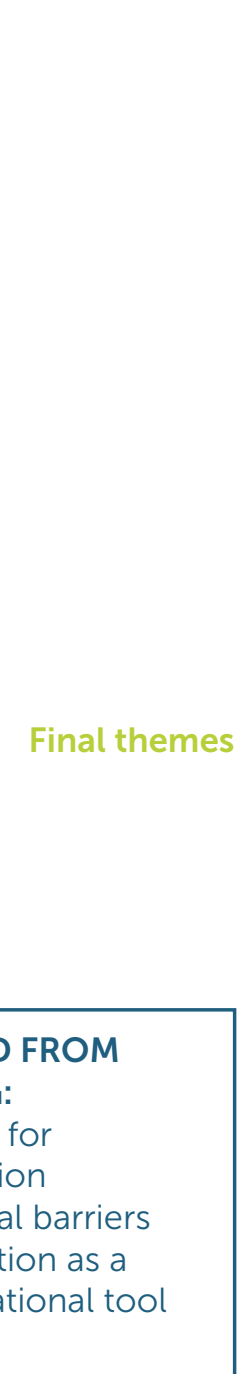

\section{DELETED FROM \\ CODING: \\ 1. Asking for \\ validation \\ 2. Minimal barriers \\ 3. Education as a \\ motivational too}

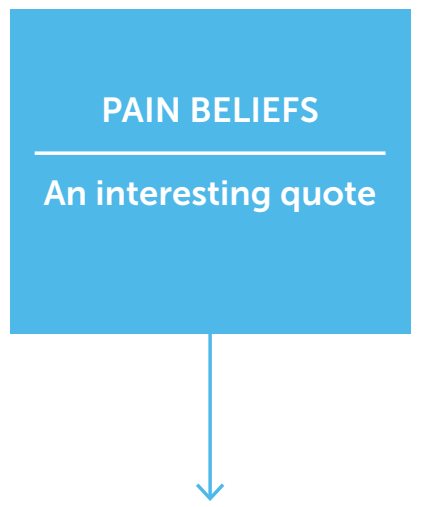

Social work

How do we currently define pain?

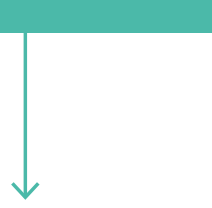

Variability in the comprehension of pain assumptions and beliefs
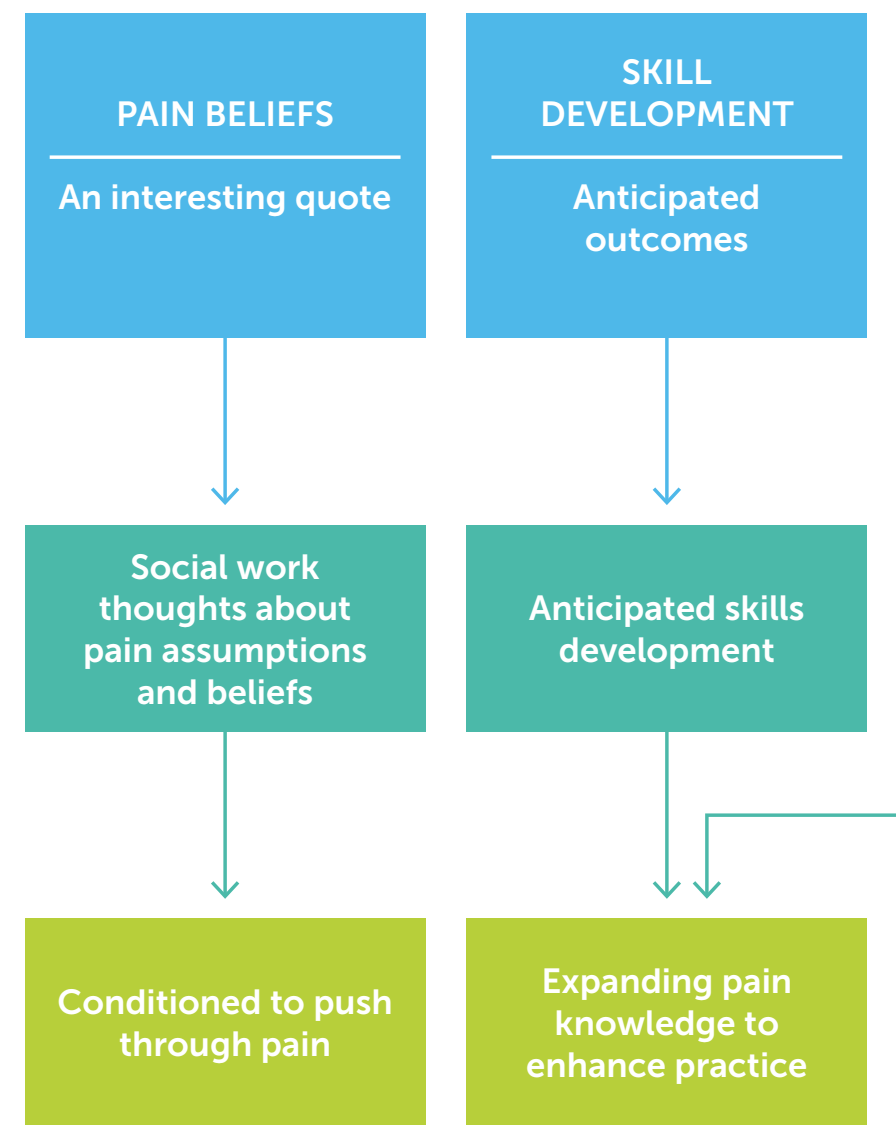

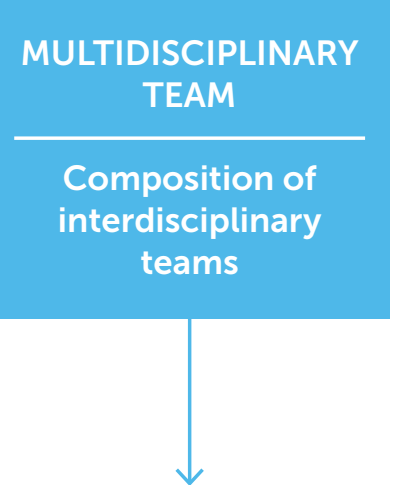

Working in interdisciplinary teams

\section{SOCIAL WORK ROLE}

Autonomy of role

Autonomy of role

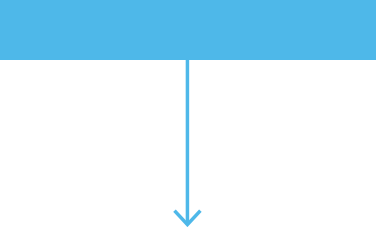

Practicality of social work role
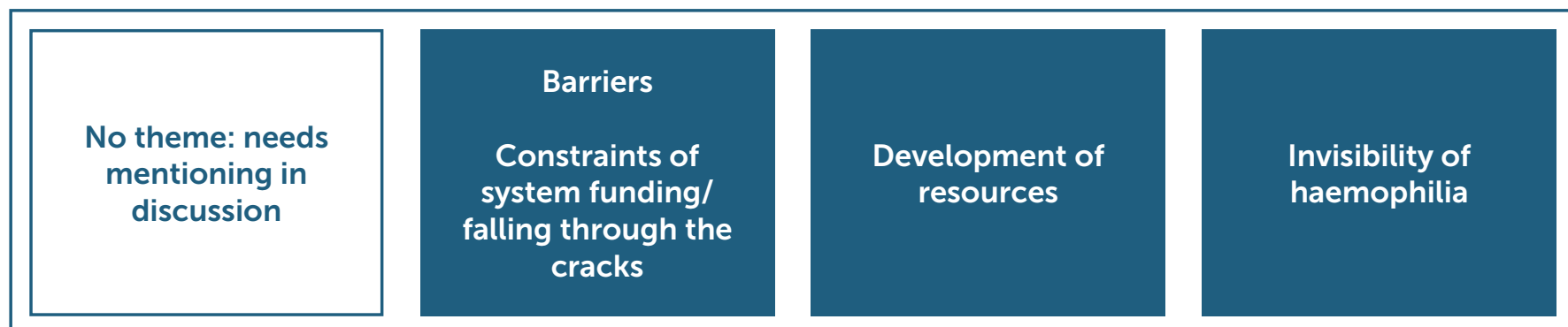

Impact of pain on...

Focus of social

impact of pain/

functional effects

of pain 


\section{APPENDIX}

Interview guide

\section{Jennifer King}

Final Interview Guide: SW knowledge of pain assessment and management in bleeding disorders

April 12/13, 2018

\section{Current Practice:}

1. Can you describe your work in bleeding disorders care?

2. Can you tell me if, and how you believe pain affects the patients you see with bleeding disorders? What role have you played in helping these individuals?

What are barriers to your work in caring for a patient with pain?

\section{Current Understanding of Pain:}

1. Describe some of the messages you hear about pain from...

- Your family

- Society

- Medical professionals

- Bleeding disorder patients

2. *What is acute pain in bleeding disorders?

3. *What is chronic pain in bleeding disorders?

\section{Prioritized Learning:}

1. What type of pain education would make an impact on your direct clinical practice?

2. From the following list which is the most important pain topic that would have a direct impact on your practice? (From the IASP Curriculum Outline for Pain in Social Work)

- Multidimensional Nature of Pain

- Pain Assessment and Measurement

- Management of Pain

- Clinical Conditions

3. How do you respond to the following statement? "Social workers who develop pain-specific knowledge are better able to assess and advocate for appropriate care and employ evidence-informed interventions that contribute to the team management of pain and related suffering" (IASP Curriculum Outline for Pain in Social Work).

4. How would pain education have an impact on the type of care you provide for patients? 